Vol. 6, No. 3-4, 2020

\author{
Vadym Stupnytskyy ${ }^{1}$, She Xianning ${ }^{2}$ \\ ${ }^{1}$ Department of Robotics and Integrated Mechanical Engineering Technologies, \\ Lviv Polytechnic National University, St. Bandera Str. 12, Lviv, Ukraine, \\ E-mail: vadym.v.stupnytskyi@lpnu.ua, ORCID 0000-0003-0006-9932 \\ ${ }^{2}$ Department of Robotics and Integrated Mechanical Engineering Technologies, \\ Lviv Polytechnic National University, St. Bandera Str. 12, Lviv, Ukraine, \\ E-mail: 1vivshe@gmail.com, ORCID 0000-0003-1360-210X
}

\title{
RESEARCH AND SIMULATION OF THE MACHINING PROCESS OF DIFFICULT-TO-CUT MATERIALS
}

Received: November 22, 2020 / Revised: December 28, 2020 / Accepted: December 30, 2020

C Stupnytskyy V., Xianning She, 2020

\begin{abstract}
Heat-resistant and high-alloy steels and alloys are difficult materials to machine. Optimizing the cutting parameters for such materials is a complex and multi-factorial technological process planning task. The paper describes the method of analysis of loading, thermodynamic and stress-strain state of a workpiece while cutting of typical representative of hard-to-cut materials (chromium-nickel alloy IN718) using finite element simulation. Influence of feed rate on cutting force and temperature in the zone of chip formation is given. The paper also analyzes the effect of cutting edge geometry on the thermal and stress state of the workpiece during cutting. Based on the conclusions about the simulation results, an analogy can be made with the processing of such materials. This will significantly reduce the time of technological preparation and decrease the cost of experimental studies.
\end{abstract}

Keywords: difficult-to-cut materials, machinability, cutting, simulation, stress-strain state, tool wear, cutting parameters.

\section{Introduction}

In modern mechanical engineering, in particular, aviation, automobile and defense industries, the processes of cutting complex surfaces of high-tech parts are important. Most of these parts are made of hard-to-machine materials, the machinability of which is much worse than that of conventional structural materials. Common features of such alloys in comparison with structural materials are: high strength, low thermal conductivity, high heat resistance and high coefficient of hardening during plastic deformation. The combination of these factors significantly complicates the processing of such materials and causes an increase in stress, temperature in the cutting zone and the load on the tool. The use of structural materials with such properties allows to create machines with higher performance. Heat-resistant alloys retain physical and mechanical properties at a high level at temperatures from $700^{\circ} \mathrm{C}$ and, depending on the chemical composition of the alloying additives, up to $2000^{\circ} \mathrm{C}$. When machining heat-resistant steel workpieces, the cutting forces are 1.2..1.5 times greater than when machining usual low-carbon steel workpieces, and when machining parts from deformed heat-resistant alloys in about 2 times greater [1], [2], [3]. Therefore, at machining of heat-resistant and high-strength steels and alloys there is a necessity to reduce cutting speed as their machinability worsens.

Optimization of technological processes of cutting hard materials is a complex and multivariate task. The choice of cutting parameters, tool material, cutting wedge geometry, cutting edge coating, lubrication and cooling environment depends on the goal set by the technologist [4], [5], [6]. Such aim can be to achieve high productivity, low cost or effective operational properties of machined surfaces. To study these parameters, the experience gained from experimental studies is usually used, which will allow analytical 


\section{Vadym Stupnytskyy, She Xianning}

modeling of cutting such materials. However, the most modern and effective research method is rheological simulation. Analysis of the results of such simulation will allow predicting the force, stressstrain and thermal state of the workpiece and tool during cutting of the different hard-to-cut materials with the diverse parameters as well as in varied technological environments.

\section{Literature review on the machining of difficult-to-cut materials}

Comparison of the mechanical characteristics of hard high-alloy steels and conventional carbon steels shows that the values of the real limit of strength and HB hardness at normal temperature and in the absence of deformation (hardening) are approximately equal. Therefore, the poorer machinability of heatresistant and stainless steels and alloys is determined by other physical, mechanical and chemical properties and, above all, structure, mechanical characteristics, determining their properties not only in the original but also in the hardened state and when heated, as well as thermodynamic parameters, determining the properties of the material at elevated temperatures [1]. Most scientists note the following features of cutting heavy-duty heat-resistant and stainless steels and alloys.

1. The most significant reason for the complexity of processing the above materials is the large hardening of the material as a result of the process of deformation of the metal during cutting [7]. The increased hardened layer of heat-resistant metal is explained by specific features of a structure of a crystal lattice of these materials. The characteristic that determines the ductility or ability of the material to strengthen is the value of the conditional yield strength, which corresponds to 0.2 percent residual deformation to the yield strength $-\sigma_{0.2} / \sigma_{\text {YS }}$. The smaller this ratio, the more plastic material and the more work and cutting forces it requires removing the same volume of metal. The value of this ratio for heatresistant alloys is up to $0.4 \ldots 0.45$, while for usual carbon steels, this value is $0.6 \ldots 0.65$ and more. Due to the increased ability to strengthen during plastic deformation of heat-resistant alloys, the values can increase 2 times (from 600 to $1200 \mathrm{MPa}$ ), and for some alloys 3...4 times (from 300 to $1000 \mathrm{MPa}$ ), while the relative elongation decreases from $40 \ldots 65 \%$ to $5 \ldots 10 \%$.

2. Another important reason for low machinability of alloy steels is the low thermal conductivity of the workpiece, which leads to elevated temperatures in the contact zone, and hence to the activation of adhesion and diffusion, intensive welding of contact surfaces and destruction of the cutting part of the tool [8]. These phenomena do not allow the use of tools with low heat resistance in the processing of heatresistant materials. However, when using a high-capacity tool for the same reasons have to take low cutting speeds [1]. Given the poor heat dissipation in the processing of heat-resistant alloys, the main importance is the cooling properties of lubricants.

3. Scientific sources [1], [9] emphasize that an important reason for the low machinability of most heat-resistant and high-alloy steels is the ability to maintain the original strength and hardness at elevated temperatures. This property leads to a high specific load on the contact surfaces of the tool during cutting. The low thermal conductivity of these materials enhances the effect of this factor. Therefore, the high temperature on the contact surfaces does not increase the plasticity and not decrease the hardness of the cut-out layer.

4. Great abrasive wear of the cutting tool in heat-resistant and stainless steels and alloys, due to the presence of a structural phase formed by intermetallic or carbide inclusions [10]. These particles act on the working surfaces of the tool like an abrasive, leading to increased wear. Of great importance are also the structural transformations that occur in these materials in the process of plastic deformation and are accompanied by the precipitation of carbides. All the above-described solid inclusions together with high temperatures on the contact surfaces, lead to intense abrasive and diffusion wear of the cutting part of the tool due to the phenomenon of adhesion. Therefore, the coefficients of friction of heat-resistant and stainless steels are many times higher than for usual carbon steels [11], [12].

5. Reduced vibration resistance of the system "Machine-Device-Tool-Workpiece" is due to the high coefficient of hardening of heat-resistant materials with uneven flow of the process of their plastic deformation [1]. Occurrence of vibrations leads to high-frequency oscillations of power and thermal 


\section{Research and Simulation of the Machining Process of Difficult-To-Cut Materials}

parameters of cutting and vibration loading on the tool. This contributes to micro- and macro-chipping of the cutting edge. The phenomenon of chips welding with the rake face of the tool intensifies in the presence of vibrations. This creates a particularly adverse effect on the stability of the tool.

Thus, the process of cutting difficult-to-cut alloys can be described in stages: first, the working surfaces of the tool are in contact with a relatively soft, not hardened metal and under their influence, there is a plastic deformation of the cut-out layer. This is accompanied by significant energy absorption by the tool. The cut layer hardens strongly at this stage. It acquires the properties of hardened metal and becomes brittle. At this point, the supply of plasticity is exhausted and there is a shear with accompanied of the destruction of the material and the separation of chips. The low thermal conductivity of difficult-to-cut materials leads to a sharp decrease in heat dissipation in the chips and the workpiece, and hence to an increase in temperature in the contact zone of the cutting part of the tool and the workpiece. Activation of adhesion and diffusion processes is characteristic for this process. Tool wear increases significantly and build-up phenomena become more active.

In modern mechanical engineering, there are many ways to facilitate the cutting of difficult-to-cut materials, including heat-resistant alloys. The most widespread of these are methods aimed at increasing the stability of cutting tools [13]. This is effective, above all, provided the correct choice of the tool material and the geometry of the cutting wedge of the tool. The use of special lubricants and coolants is another effective method of improving the machinability of difficult-to-process materials [14]. The application of special wear-resistant coatings that significantly reduce the coefficient of friction in the contact group "tool-chip-workpiece" has great potential in improving the processing efficiency of high-alloy steels.

\section{Methods of scientific research}

A simulation model of machining with a carbide interchangeable cutter insert was created to study the influence of cutting parameters on elastically stress-strain and thermodynamic states of the machining process of difficult-to-cut alloys. The study was conducted in the Deform 2D software. It is necessary to use reliable analytical dependences, which are used by the mathematical apparatus of the software complex in order to obtain adequate prognostic models.

The initial data for the study is:

- physical and mechanical parameters of the workpiece material and tools;

- cutting parameters;

- geometrical parameters of the cutting tool wedge;

- state of the workpiece before processing;

- geometrical parameters of the workpiece.

To create a full-fledged working simulation model of the cutting process, it is necessary to take into account additional data:

- to create a formalized problem-oriented database on the physical and mechanical characteristics of the machined and tool material (mechanical and thermodiffusion characteristics, curves of thermodynamic hardening of materials, their structural and phase state before machining, etc.);

- choose the material's Ultimate yield stress;

- method of iterative calculation (Newton-Raphson or Direct Iterative Method) and the corresponding solver (Skyline or the Sparse), formed using the Finite Element Method (FEM);

- choose the selection algorithm and methods of calculating the destruction criterion;

- method of calculating the error of the results convergence;

- method of selection and features of generating Lagrangian or Euler meshes for FEM analysis.

The DEFORM 2D uses an intelligent grid generator to build the grid, which is able to rebuild the mesh during the calculation process and divides the cutting area into sections with different grid sizes. Reducing the size of the lattice edge is used for the cutting area and adjacent areas of the workpiece and tool, and increase, respectively, for the outer parts of the workpiece and tool, which is sufficient to obtain a clear picture for the cutting process without spending of the memory additional resources. The analysis of 


\section{Vadym Stupnytskyy, She Xianning}

the obtained simulation results will allow to establish the current and residual stress-strain and thermodynamic parameters, which, as a result, will form patterns of changes in important performance characteristics of the product from the structure and parameters of the manufacturing process.

Given study requires a series of simulations to determine the characteristics of the stress-strain and thermodynamic state of the surfaces formed during their machining and the relationship of cutting parameters (in our case from changing tool feed and changing the tool rake angle).

The investigated chromium-nickel alloy IN718 belongs to the group of heat-resistant materials and has the following properties:

- Ultimate Tensile Strength: $\sigma_{U T S}=720 \mathrm{MPa}$;

- Ultimate Yield Strength: $\sigma_{\mathrm{YS}}=360 \mathrm{MPa}$;

- reduction of area: $\psi=50 \%$;

- density: $\rho=7900 \mathrm{~kg} / \mathrm{m}^{3}$.

The value of the cutting speed (Surface speed $(\mathrm{v}=100 \mathrm{~m} / \mathrm{min}))$ is selected for all studies and does not change according to the conditions of our study. The value of the tool feed (Feed rate (f)) changes for four experiments and take values: $0.1 \mathrm{~mm} / \mathrm{rev}, 0.25 \mathrm{~mm} / \mathrm{rev}, 0.4 \mathrm{~mm} / \mathrm{rev}$ and $0.6 \mathrm{~mm} / \mathrm{rev}$ (Fig. 1).

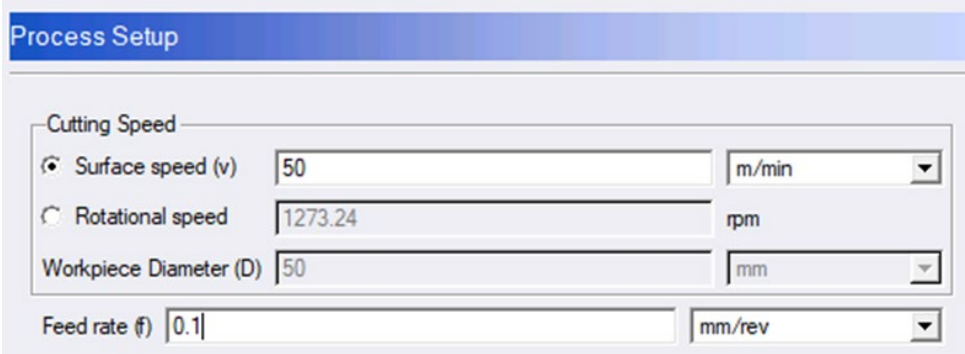

Fig. 1. Setting the parameters of the technological process

The geometric parameters of the tool are set only for the cutting edge, and the general dimensions and cross section of the holder are not taken into account (Fig.2).

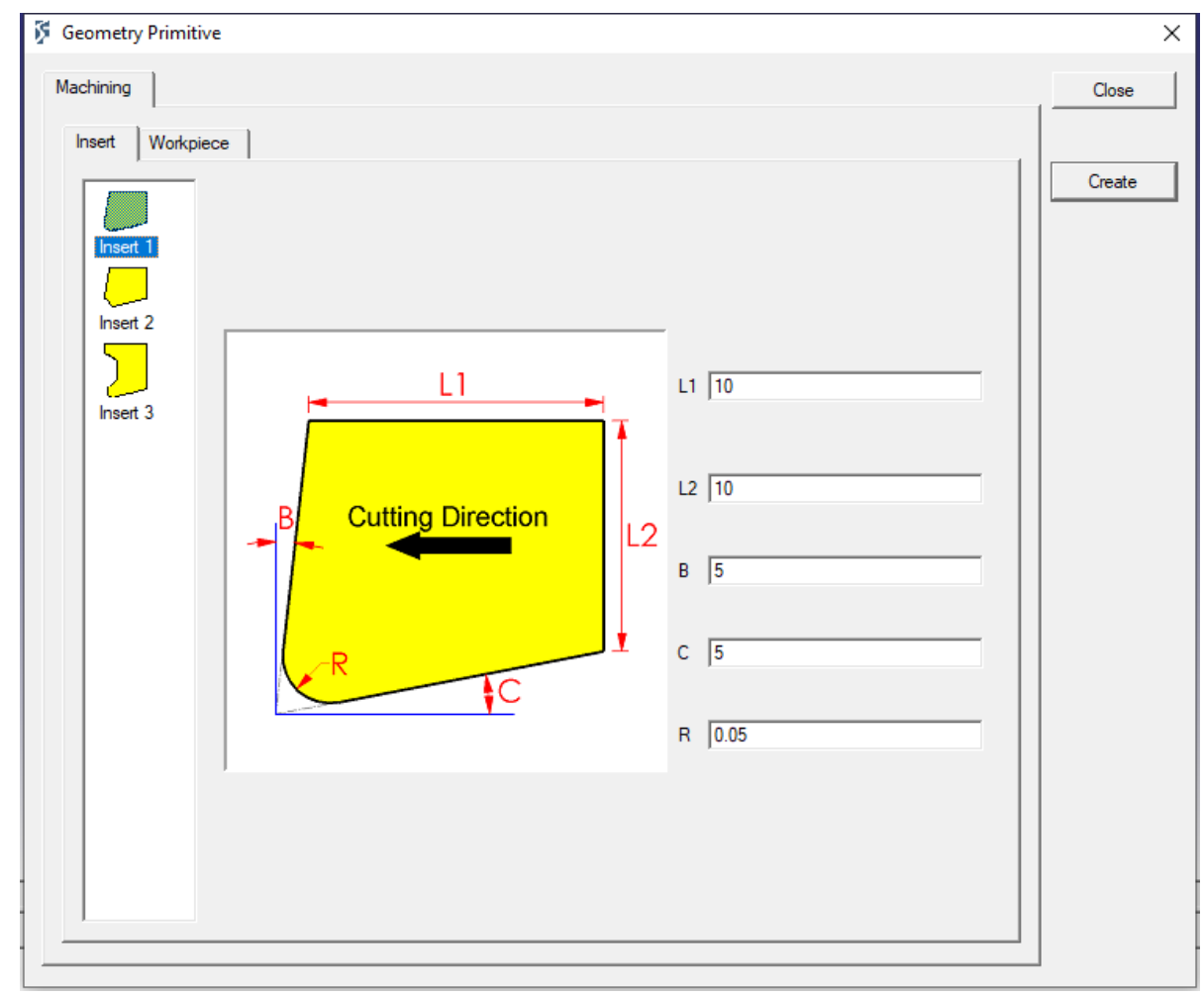

Fig. 2. Setting the parameters of the technological process 
Selection of tool material from the software library of materials. An alloy based on tungsten carbide (WC) was chosen for these studies.

The overall dimensions of the investigated workpiece (Fig. 3) are based on the introduction of similar overall dimensions of the parts, which were studied in the process of experimental dependencies in previous scientific papers for the possibility of comparing the results of research [1], [14].

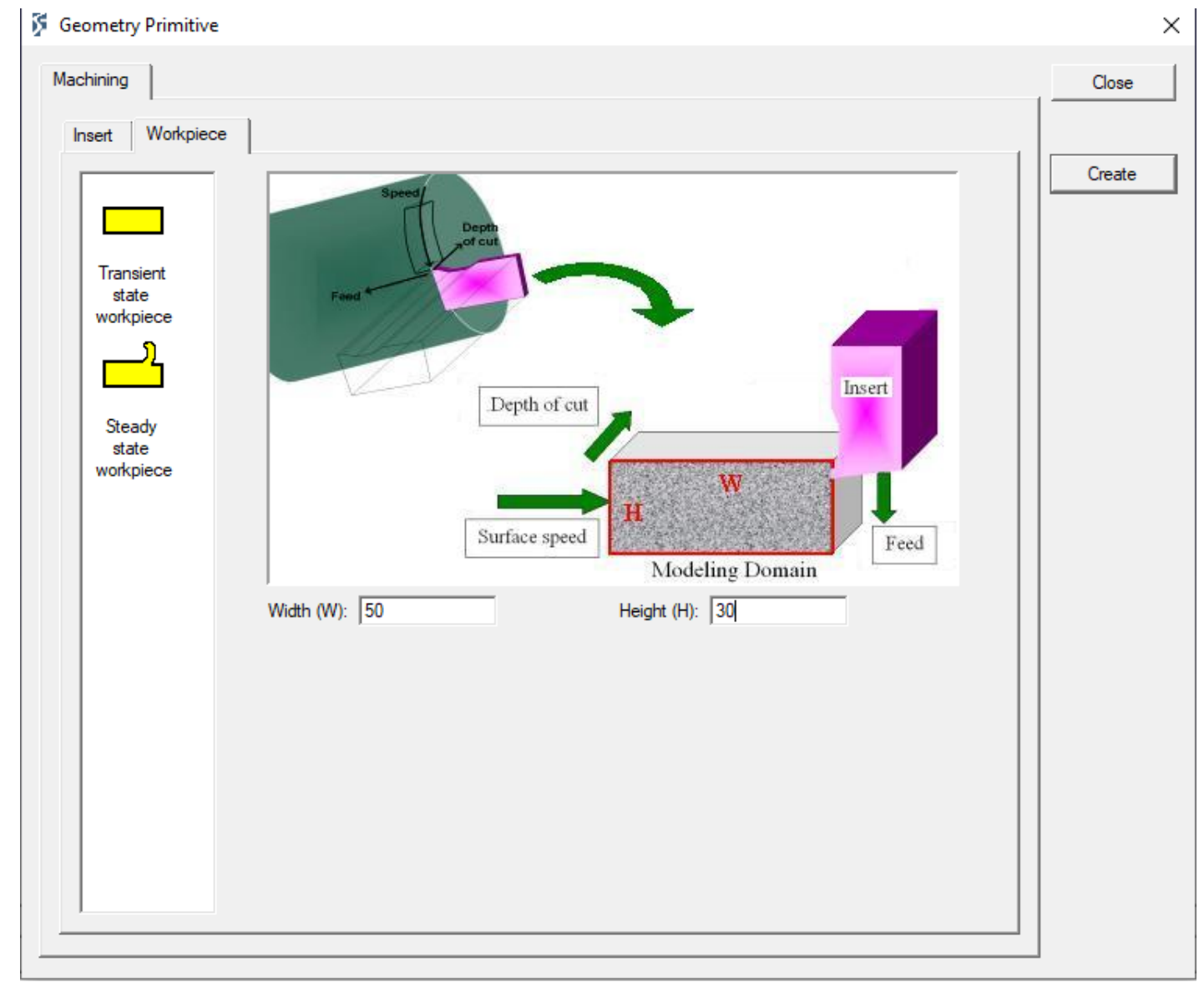

Fig. 3. Setting the geometry primitive of the workpiece

At this stage, the parameters of the machining process are set:

- number of steps (the total number of iterations of the model calculation) is 38000 ;

- number of steps to simulation database is 10 ;

- total length of processing is $50.75 \mathrm{~mm}$.

\section{Analysis of the dependence of the cutting force, stress-strain and thermal state of the hard-to-cut workpiece on the tool feed rate}

To analyze the study after simulation the cutting process, a database of all parameters was formed separately for each model and a number of parameters were selected to compare the results. No calculations were performed for the temperature and stress parameters, but the maximum values observed in the cutting zone were selected from the data set obtained during modeling. From the obtained array, graphs of dependences were formed, which make it possible to determine the effect of feed on the stress-strain and thermodynamic state of the material during turning of heat-resistant chromium-nickel alloy IN718.

Based on the analysis of the simulated results of the study, graphical dependences of the cutting force during processing were formed for four feed values: 0.1 millimeters per revolution (MMPR), 0.25 MMPR, 0.4 MMPR and 0.6 MMPR (Fig. 4). The graph can be separated into two parts: the first is the beginning of the incision of the cutter into the material (part of the non-constant machining process in the period 0 to $1 \mu \mathrm{sec}$ processing time) and part of the established cutting process (from 1 to $20 \mu \mathrm{sec}$ and beyond). 


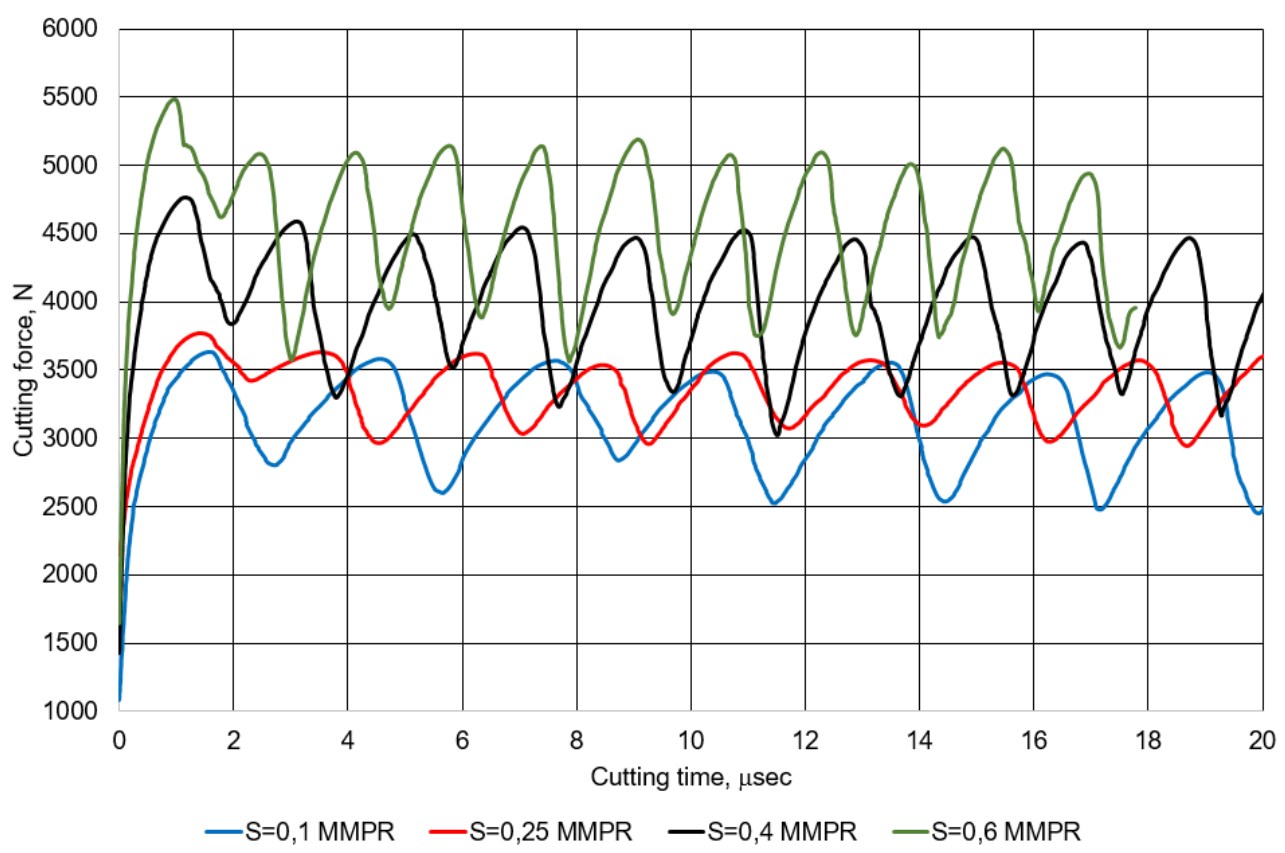

Fig. 4. Graph of changes in cutting force during turning of heat-resistant chromium-nickel alloy IN718

The analysis of the graph makes it possible to conclude that the transition to a stable mode of operation occurs at approximately the same time, regardless of changes in cutting parameters (feed values). This value is approximately equal to $1 \mu \mathrm{sec}$ of machining time. At the stage of the steady-state processing state, the maximum amplitude values of the cutting force are:

- for feed rate 0.1 millimeters per revolution (MMPR), the average value of the cutting force is $3442 \mathrm{~N}$;

- for feed rate 0.25 MMPR, the average value of the cutting force is $3572 \mathrm{~N}$;

- for feed rate 0.4 MMPR, the average value of the cutting force is $4350 \mathrm{~N}$;

- for feed rate 0.6 MMPR, the average value of the cutting force is $5011 \mathrm{~N}$.

Therefore, when increasing the feed value, the cutting force at all values increases compared to the feed 0.1 MMPR as follows:

- for 0.25 MMPR increases by $3.8 \%$;

- for 0.4 MMPR increases by $26.4 \%$;

- for 0.6 MMPR increases by $45.6 \%$.

This trend is completely correlated with theoretical data [1] and known experimental results [14].

Similar to the results of the study described above, the cutting process can be divided into the zone of steady-state cutting mode (from $2 \mu \mathrm{sec}$ ) and transient mode (from 0.8 to $2 \mu \mathrm{sec}$ ). In the period from 0 to $0.8 \mu \mathrm{sec}$, the in-cutting process takes place, which is characterized by the predominant tensile stress in the primary zone of chip formation. Therefore, in the graph (Fig. 5), shear deformations, which are a priority in the equivalent stress, occur with a delay of approximately $0.8 \mu \mathrm{sec}$.

Analysis of the simulation results shown in Fig. 5, allows us to conclude that the values of the effective stress when cutting a hard-to-treat heat-resistant alloy IN718 alloy increase with increasing feed. This completely coincides with the increase in cutting forces. From the obtained data, the simulated effective stress represents the following values:

- for the feed rate $0.1 \mathrm{MMPR}$, the average effective stress value is approximately $1612 \mathrm{MPa}$;

- for the feed rate $0.25 \mathrm{MMPR}$, the average stress value is about $1617 \mathrm{MPa}$;

- for the feed rate 0.4 MMPR, the average stress value is about $1620 \mathrm{MPa}$;

- for the feed rate 0.6 MMPR, the average stress value is about $1624 \mathrm{MPa}$.

That is, to conclude that the stress value in these cutting parameters depends not so great on the feed. If we calculate the increase in effective stress depending on the increase in feed rate, we obtain the following results: 
- at increase of feed 0.25 MMPR in comparison with feed $0.1 \mathrm{~mm}$ MMPR, increase is only on $0.31 \%$;

- at increase of feed 0.4 MMPR in comparison with feed $0.1 \mathrm{~mm}$ MMPR, increase is only on $0.5 \%$;

- at increase of feed 0.6 MMPR in comparison with feed $0.1 \mathrm{~mm}$ MMPR, increase is only on $0.75 \%$;

According to the simulated results, the greatest stress occurs in the shear zone, at the beginning of the shear of the chips and its separation from the workpiece.

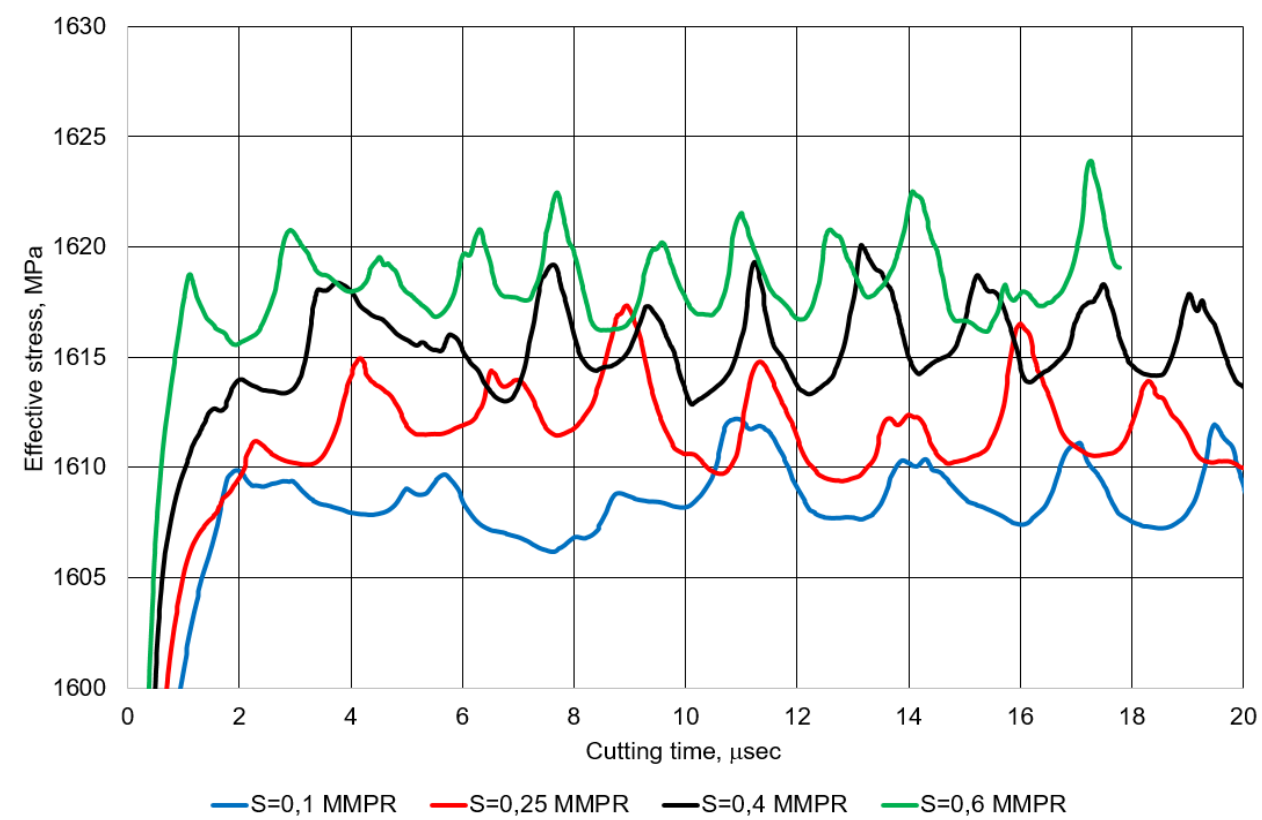

Fig. 5. Graph of change of the maximum value of equivalent stress in the primary zone of chip formation

The cutting temperature of the heat-resistant alloy IN718 in the steady state increases with increasing feed rate value (Fig. 6):

- when feeding is 0.1 MMPR, the average temperature in the cutting zone is approximately $975^{\circ} \mathrm{C}$;

- when feeding is $0.25 \mathrm{MMPR}$, the average temperature in the cutting zone is approximately $1024^{\circ} \mathrm{C}$;

- when feeding is $0.4 \mathrm{MMPR}$, the average temperature in the cutting zone is approximately $1068^{\circ} \mathrm{C}$;

- when feeding is $0.6 \mathrm{MMPR}$, the average temperature in the cutting zone is approximately $1097^{\circ} \mathrm{C}$.

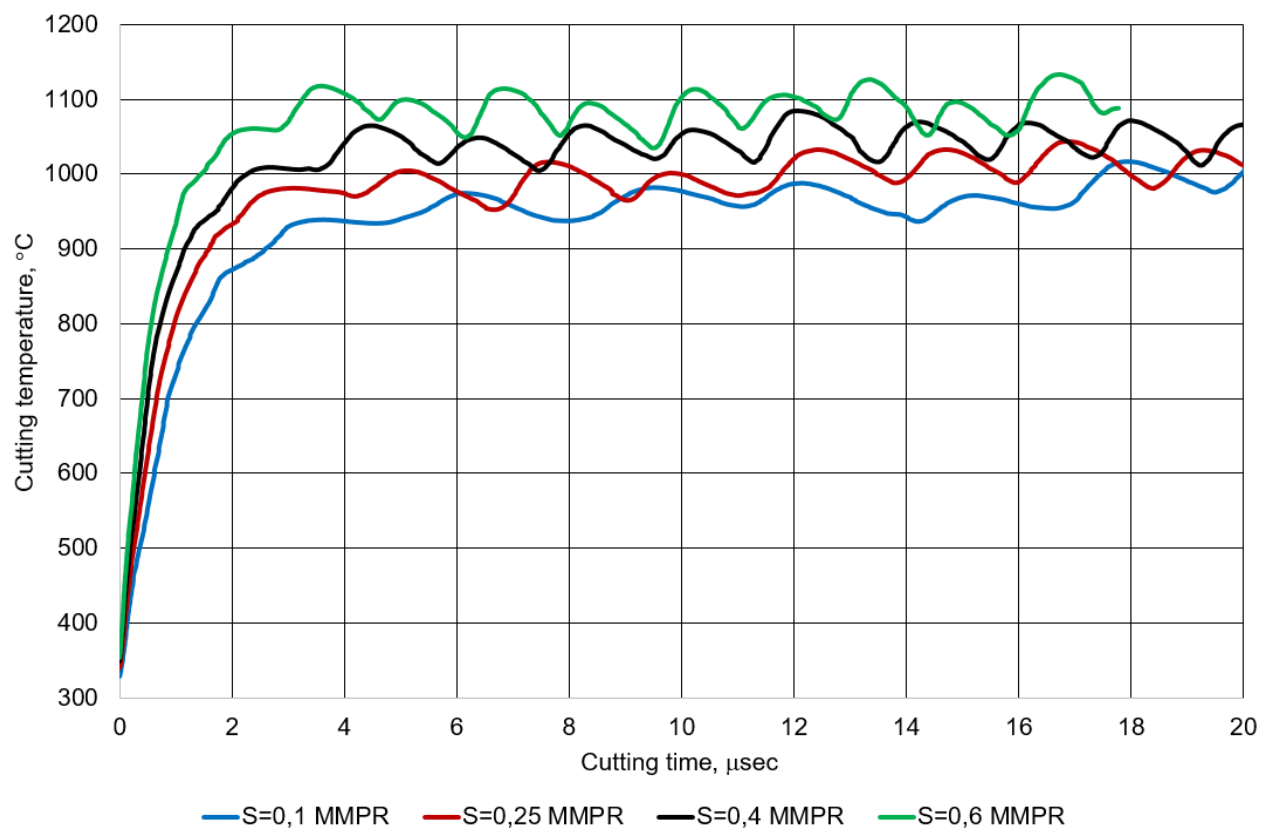

Fig. 6. Graph of the dependence of the maximum temperature in the cutting zone during the processing of heat-resistant alloy IN718 


\section{Vadym Stupnytskyy, She Xianning}

Such results can be explained by the increase in the speed of the chips on the rake face of the tool, which increases the amount of heat released due to friction.

\section{Analysis of the influence of the tool rake angle on the cutting temperature and loading}

Simulation of the thermodynamic state of the cutting zone to check the influence of the rake angle of the tool was performed. All simulation studies were conducted at a feed rate 0.25 MMPR. The following values of the thermal state were obtained by simulation (Fig. 7):

- for the tool rake angle $10^{\circ}$ the average temperature is about $1024^{\circ} \mathrm{C}$;

- for the tool rake angle $5^{\circ}$ the average temperature is about $1094^{\circ} \mathrm{C}$;

- for the tool rake angle $0^{\circ}$ the average temperature is about $1211^{\circ} \mathrm{C}$.

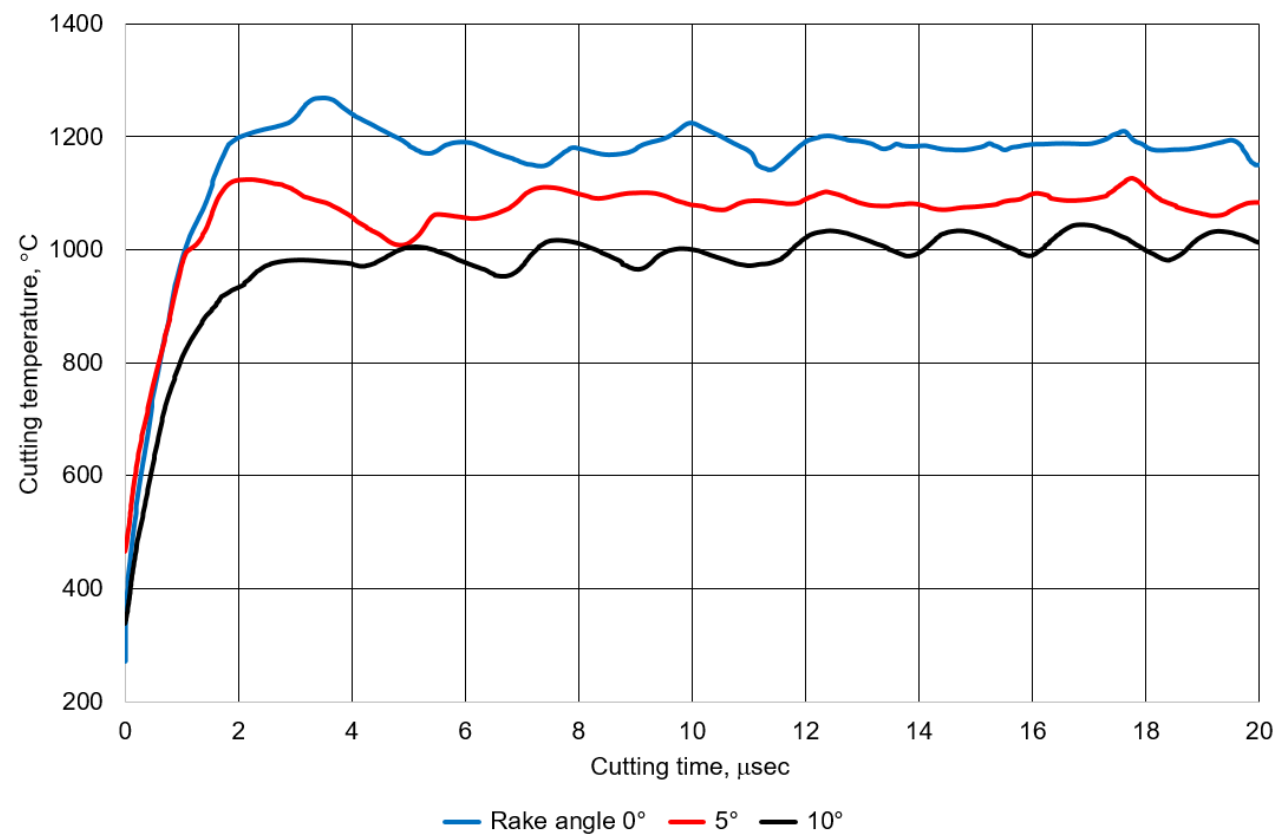

Fig. 7. Graph of temperature in the cutting zone for different rake angles of the tool

Increasing the tool rake angle causes a rise in temperature in the cutting zone (Fig. 7). It is due to the greater pressure of the chips on the rake face of the cutter and the increase in the frictional load on the cutting wedge. As a percentage, we obtain the following increase:

- at decreasing the rake angle from $10^{\circ}$ to $5^{\circ}$ the cutting temperature increase is $6.39 \%$;

- when the rake angle is reduced from $10^{\circ}$ to $0^{\circ}$, the cutting temperature rise is $9.66 \%$.

For the steady-state cutting mode of the heat-resistant chromium-nickel alloy IN718, an increase in the cutting force is observed with a decrease in the angle of the rake face (Fig. 8). The results of simulation are as follows:

- for the rake angle $10^{\circ}$ we obtain the total cutting force about $3535 \mathrm{~N}$;

- for the rake angle $5^{\circ}$ the total cutting force is about $3796 \mathrm{~N}$;

- for the rake angle $0^{\circ}$ the total cutting force is about $4440 \mathrm{~N}$.

The increase in cutting force to change the value of the rake angle relative to the value of $10^{\circ}$ as a percentage is:

- for tool rake angle $5^{\circ}$ the total cutting force will increase by $6.87 \%$;

- for $0^{\circ}$ - the force will increase by $14.5 \%$.

\section{Conclusions}

1. When increasing the feed rate during hard alloy IN718 machining the total loading increases compared to the feed $0.1 \mathrm{~mm}$ per revolution (MMPR) as follows: for 0.25 MMPR the cutting force increases by $3.8 \%$; for 0.4 MMPR increases by $26.4 \%$; for 0.6 MMPR increases by $45.6 \%$. This trend is completely correlated with the theoretical data and known experimental results. 


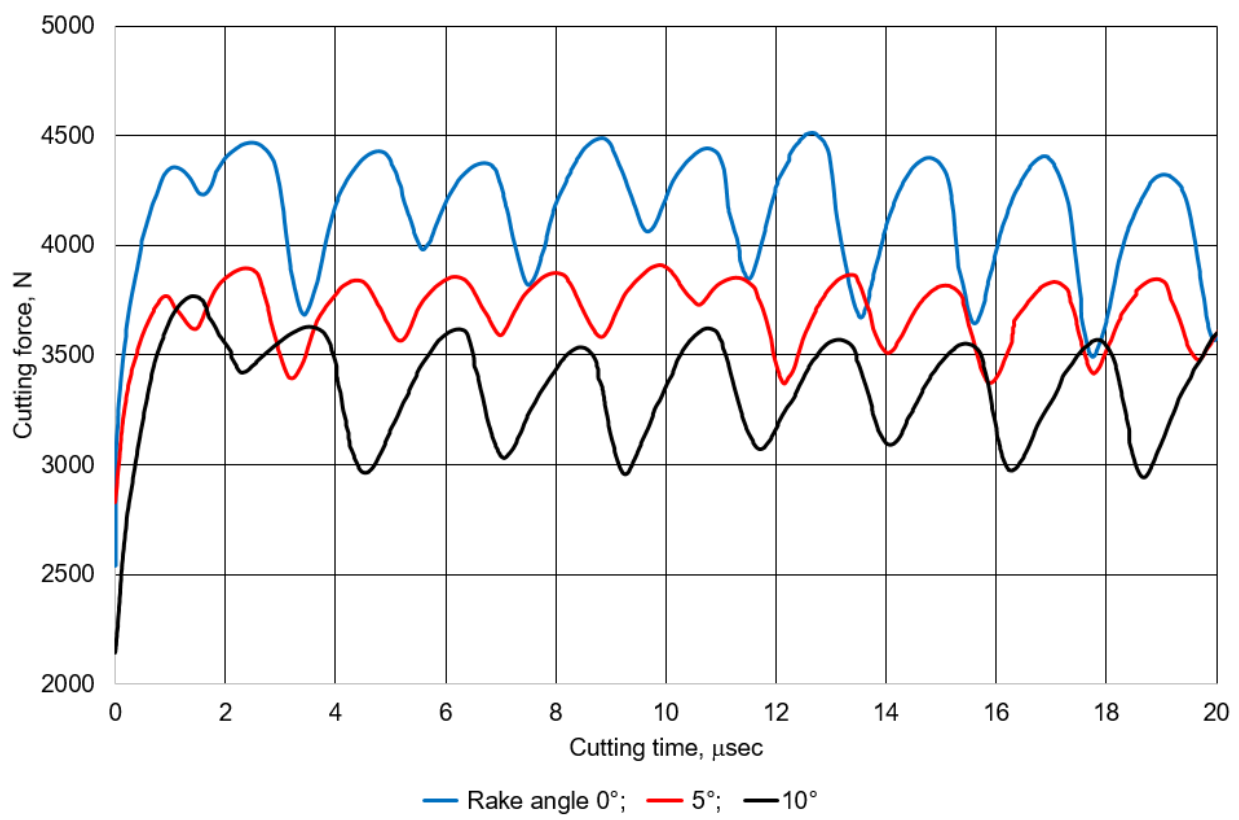

Fig. 8. Graph of the dependence of the cutting force for different tool rake angles

2. Analysis of the simulation results allows us to conclude that the values of the effective stress when cutting a hard-to-treat heat-resistant alloy IN718 alloy increase with increasing feed. This completely coincides with the increase in cutting forces. The simulated effective stress represents the following values: for the feed rate 0.1 MMPR, the average effective stress value is approximately $1612 \mathrm{MPa}$; for the feed rate $0.25 \mathrm{MMPR}$ it is about $1617 \mathrm{MPa}$; for the feed rate $0.4 \mathrm{MMPR}$ the average stress is about $1620 \mathrm{MPa}$ and for the feed rate 0.6 MMPR it is about $1624 \mathrm{MPa}$. That is, to conclude that the stress value in these cutting parameters depends not so great on the feed.

3. The cutting temperature of the heat-resistant alloy IN718 in the steady state. When feeding is $0.1 \mathrm{MMPR}$, the average temperature in the cutting zone is approximately $975^{\circ} \mathrm{C}$; for the feed $0.25 \mathrm{MMPR}$ it is approximately $1024^{\circ} \mathrm{C}$; for $0.4 \mathrm{MMPR}$, the average temperature is about $1068^{\circ} \mathrm{C}$ and when feeding is 0.6 MMPR, the temperature will be about $1097^{\circ} \mathrm{C}$. Such results can be explained by the increase in the speed of the chips on the rake face of the tool, which increases the amount of heat released due to friction.

4. Increasing the tool rake angle causes a rise in temperature in the cutting zone. This is due to the greater pressure of the chips on the rake face of the cutter and the increase in the frictional load on the cutting wedge. As a percentage, we obtain the following increase: at decreasing the rake angle from $10^{\circ}$ to $5^{\circ}$ the cutting temperature increase is $6.39 \%$; when the rake angle is reduced from $10^{\circ}$ to $0^{\circ}$, the cutting temperature rise is $9.66 \%$.

5. For the steady-state cutting mode of the heat-resistant chromium-nickel alloy IN718, an increase in the cutting force is observed with a decrease in the angle of the rake face. The increase in cutting force to change the value of the rake angle relative to the value of $10^{\circ}$ as a percentage is: for tool rake angle $5^{\circ}$ the total cutting force will increase by $6.87 \%$; for $0^{\circ}$ - the force will increase about $14.5 \%$.

6. Analysis of the results of rheological simulation of the cutting process of chromium-nickel alloy IN718 has the possibility of problem-oriented selection of optimal cutting parameters and tool geometry to provide force and thermodynamic conditions of machining. This alloy is the most typical representative of difficult-to-cut materials. Based on the conclusions about the simulation results, an analogy can be made with the processing of such materials. It will significantly reduce technological preparation time and decrease the cost of experimental research.

\section{References}

[1] J. Paulo Davim, et al., Machining of Hard Materials. London: Springer-Verlag, 2011.

[2] W. König, R. Komanduri, H. K. Tönshoff, G. Ackershott, "Machining of Hard Materials", CIRP Annals, vol. 33, issue 2, pp. 417-427, 1984. 


\section{Vadym Stupnytskyy, She Xianning}

[3] F. Bleicher, D. Finkeldei, A. Siller, "Machining of Difficult-To-Cut Materials", in Proc. of the 27 DAAAM International Symposium, Vienna, Austria, 2016, pp. 0473-0479.

[4] V. Stupnytskyy, She Xianning, "Comparative Analysis of Simulation Results of Hard-to-Cut Materials Machining by Coated Cutting Tools”, Journal of Mechanical Engineering - Strojnícky časopis, vol. 70, no. 2, pp. 153-166, 2020.

[5] Nazma Sultana, Nikhil Ranjan Dhar, Prianka Binte Zaman, "A Review on Different Cooling/Lubrication Techniques in Metal Cutting”, American Journal of Mechanics and Applications, vol. 7, no. 4, pp. 71-87, 2019.

[6] A. Anand, A. Behera, S. R. Das, "An overview on economic machining of hardened steels by hard turning and its process variables", Manufacturing Review, vol. 6, no. 4, pp. 95-109, 2019.

[7] S. P. F. C. Jaspers, J. H. Dautzenberg, "Material behaviour in metal cutting: strains, strain rates and temperatures in chip formation”, Journal of Materials Processing Technology, vol. 121, no. 1, pp. 123-135, 2002.

[8] V. F. C. Sousa, F. J. G. Silva, "Recent Advances on Coated Milling Tool Technology - A Comprehensive Review", Coatings, vol. 10, no. 235, pp. 1-26, 2020.

[9] Suha Karim Shihab, Zahid A. Khan, Aas Mohammad, Arshad Noor Siddiquee, "A review of turning of hard steels used in bearing and automotive applications", Production and Manufacturing Research, vol. 2, no. 1, pp. 24-49, 2014.

[10] G. A. Ibrahim, C. H. Che Haron, J. A. Ghani, "Tool Wear Mechanism in Continuous Cutting of Difficult-to-Cut Material under Dry Machining”, Advanced Materials Research, vols. 126-128, pp. 195-201, 2010.

[11] J. P. Davim, et al., Tribology in Manufacturing Technology. Berlin, Germany: Springer, 2013.

[12] A. G. Suslov, "To the problem of friction and wear of machinery", Friction and Wear, vol. 5, pp. 801-807, 1990.

[13] F. Klocke, K. Arntz, G. F. Cabral, M. Stolorz, M. Busch, "Characterization of Tool Wear in High-Speed Milling of Hardened Powder Metallurgical Steels”, Advances in Tribology, vol. 2011, Article ID 906481, 2011.

[14] A. Hossam, Kishawy Ali Hosseini, Machining Difficult-to-Cut Materials. Cham: Springer, 2019. 